\title{
Listeria spp. em carpaccio de carne bovina e perfil de resistência aos agentes antimicrobianos
}

\section{Listeria ssp. in beef carpaccio and resistance profile to antimicrobial agents}

\author{
Stefani Faro de Novaes ${ }^{1 *}$, Vinicius de Oliveira Alves ${ }^{1}$, Marilu Lanzarin ${ }^{1}$, Daniel Oster Ritter ${ }^{1}$, \\ Robson Maia Franco ${ }^{1}$
}

RESUMO: O presente estudo foi conduzido com o objetivo de verificar a ocorrência de Listeria spp. em 50 amostras de carpaccio de carne bovina comercializados em bares e restaurantes do município de Niterói, Rio de Janeiro, e avaliar o perfil de resistência dos isolados aos agentes antimicrobianos utilizados no tratamento de infecçóes. Constataram-se que $20 \%$ das amostras obtidas de restaurantes e 35\% de bares estavam contaminadas com Listeria spp. Dentre as espécies, L. welshimeri foi isolada com maior frequência (81,82\%), seguida de $L$. grayi, $(13,66 \%)$ e $L$. monocytogenes $(4,55 \%)$, sendo o ágar Oxford o meio de plaqueamento mais eficiente para isolamento. Foi verificada a ocorrência de resistência dos isolados frente a todos os agentes antimicrobianos testados, exceto à tetraciclina, diante da qual $95,5 \%$ dos isolados apresentaram sensibilidade. A multirresistência foi verificada em $68,75 \%$ das estirpes analisadas. Desta forma, concluiu-se que o consumo de carpaccio de carne bovina representa risco potencial, constituindo um grave problema de saúde coletiva, especialmente devido à confirmação de estirpes patogênicas e resistentes aos principais agentes antimicrobianos utilizados no tratamento de listeriose.

PALAVRAS-CHAVE: antimicrobianos; bares; higiene; Listeria monocytogenes; restaurantes; segurança alimentar.

\begin{abstract}
The present study was conducted to verify the occurrence of Listeria spp. in 50 samples of beef carpaccio sold in bars and restaurants; and to evaluate the resistance profile to antimicrobial agents used in the routine treatment of infections. It was found that $20 \%$ of samples from restaurants and $35 \%$ from bars were contaminated with Listeria spp. Among the species, L. welshimeri was most frequently isolated $(81.82 \%)$, followed by L. grayi, $(13.66 \%)$ and L. monocytogenes (4.55\%). The Oxford agar plating medium was the most efficient. The resistant behavior occurred to all antimicrobial agents tested, except tetracycline, to which $95.5 \%$ of the strains were sensitive. Multidrug resistance was observed in $68.75 \%$ of the strains analyzed. Thus, it is concluded that the consumption of beef carpaccio represents a potential risk, and a serious public health problem, especially due to the confirmation of pathogenic strains that are resistant to major antimicrobial agents used in the treatment of listeriosis.
\end{abstract}

KEYWORDS: antibiotics; bars; hygiene; Listeria monocytogenes; restaurants; food security. 


\section{INTRODUÇÃO}

A carne bovina é uma excelente fonte de proteínas de alto valor biológico, de vitaminas do complexo $\mathrm{B}$ e minerais essenciais, como ferro e zinco. $\mathrm{O}$ elevado valor nutritivo associado às características sensoriais excepcionais faz com que a carne seja considerada um dos alimentos mais valorizados pelo consumidor. Nos últimos anos, o carpaccio de carne bovina se tornou um produto muito popular, facilmente encontrado em bares e restaurantes, o qual consiste em finas fatias de carne crua, preparadas a partir do músculo semitendinoso dos bovinos, tradicionalmente ingerido cru, com azeite, queijo parmesão e especiarias diversas (LuCQuin et al., 2012). Apesar do amplo consumo, os produtos cárneos, particularmente aqueles que passam por maior manipulação, constituem um excelente meio de cultura devido à elevada umidade, ao $\mathrm{pH}$ próximo da neutralidade e à composição rica em nutrientes, favorecendo a instalação, a sobrevivência e a multiplicação de microrganismos capazes de provocar doenças, como Listeria spp., que se desenvolvem na carne estocada sob temperatura de refrigeração (OrdóNEEZ, 2005; Mantilla et al., 2007).

O gênero Listeria spp. é composto por bastonetes gram positivos, não produtores de esporos e anaeróbios facultativos, cuja transmissão pode ocorrer tanto por contato direto quanto indireto com fontes contaminadas, por via oral, ocular, cutânea, respiratória e urogenital (Holt et al., 1994). Entretanto, a transmissão por ingestấo de alimentos contaminados parece ser a forma mais importante, visto que espécies de Listeria têm sido isoladas de diferentes produtos, tais como leite cru e pasteurizado, queijos, carne bovina, carne moída de diferentes animais, produtos cárneos crus e também de equipamentos e utensílios em plantas de processamento de carne bovina (Barros et al., 2004; Franco; LANDGraf, 2007; KovaCevic et al., 2012; Mantilla et al., 2007; Soriano et al., 2001; YüCEL et al., 2005). Essas bactérias estão envolvidas em um grande número de surtos de origem alimentar por todo o mundo; e os alimentos mais incriminados são aqueles prontos para consumo, que são armazenados por longos períodos em refrigeração, principalmente os produtos cárneos (Ingham et al., 2004).

Dentre as espécies, Listeria monocytogenes é considerada a mais patogênica para os humanos e determina doença cujos sintomas incluem septicemia, meningite, encefalite e infecçáo cervical ou intrauterina em gestantes, que pode provocar abortamento. Outros danos podem ocorrer, como endocardite, abscessos, lesóes cutâneas, além de sintomas gastrointestinais e outros semelhantes aos da gripe (SiLVA et al., 2010). Essa espécie é considerada um patógeno emergente capaz de ocasionar doenças por meio da ingestáo de alimentos contaminados, principalmente aqueles que náo foram submetidos a tratamento térmico antes do consumo, como o carpaccio. Esse alimento, além de possuir maior área de superfície e de ser altamente manipulado, possibilitando o crescimento bacteriano, permite o desenvolvimento de bactérias psicrotróficas patogênicas como Listeria spp., pois permanecem estocados sob temperatura de refrigeração até o consumo (Mantilla et al., 2007).

A preocupação é ainda maior quando se trata de estirpes resistentes aos principais agentes antimicrobianos utilizados no tratamento da listeriose, configurando um problema adicional que dificulta o combate às infecçôes alimentares, gerando um risco considerável para saúde coletiva (Mantilla et al., 2008a).

Sendo assim, objetivou-se com o presente estudo pesquisar a ocorrência de estirpes de Listeria spp. em carpaccios de carne bovina comercializados em bares e restaurantes locais, comparar a eficiência de isolamento em diferentes meios de cultivo e avaliar o perfil de resistência das estirpes isoladas aos agentes antimicrobianos utilizados na rotina do tratamento de infecçôes alimentares.

\section{MATERIAL E MÉTODOS}

Foram coletadas aleatoriamente 50 amostras de carpaccio de carne bovina, em 20 bares e 30 restaurantes do município de Niterói, no estado do Rio de Janeiro, nas condiçóes oferecidas ao pronto consumo, no período de 2011 a março de 2012. O estudo observacional foi delineado de modo transversal onde cada amostra correspondeu a um estabelecimento. Para o cálculo amostral foi utilizado o método de amostragem descrito por Di Giacomo; Koepsell (1986) e Manrtin et al. (1987), baseando-se na prevalência previamente estimada de $15 \%$ com probabilidade de erro de $10 \%$, encontrada em trabalhos semelhantes anteriormente revisados.

Para a colheita foram utilizados utensílios sanitizados com álcool a 70\% e as amostras de carpaccio, sem molhos e temperos, foram acondicionadas em embalagens plásticas estéreis (Bag Light ${ }^{\circledR}$ 001574) devidamente fechadas e identificadas. As embalagens contendo as amostras foram acondicionadas em recipiente isotérmico contendo sachês de gelo em gel reutilizáveis, e encaminhadas ao Laboratório de Controle Microbiológico da Faculdade de Veterinária da Universidade Federal Fluminense, onde permaneceram estocadas a $4^{\circ} \mathrm{C}$ até a realização das análises bacteriológicas em no máximo 24 horas após a colheita, respeitando os limites propostos pelo Compendium of Methods for the Microbiological Examination of Foods (Midura; Bryant, 2001).

\section{Preparo e diluição das amostras}

No interior da câmara asséptica, as amostras foram abertas com assepsia na zona de segurança da chama do bico de Bunsen. Com auxílio de instrumentos flambados ao rubro e esfriados, foram retirados e pesados em balança (Martec ${ }^{\circledR}$ LC1) 25 gramas da amostra e adicionados em $225 \mathrm{~mL}$ de caldo Universidade 
de Vermont modificado (UVM) (Difco ${ }^{\circledR} 222330$ ), em embalagem estéril para homogeneização em stomacher (Seward ${ }^{\circledR}$ $80)$ em velocidade de $265 \mathrm{rpm}( \pm 5 \%)$, durante 2 minutos.

\section{Identificação e isolamento de Listeria spp.}

O método analítico utilizado é descrito pela Instrução Normativa no 62 do Ministério da Agricultura, Pecuária e Abastecimento (BRASIL, 2003), sendo que foram empregados dois meios alternativos para plaqueamento seletivo de Listeria spp.

A amostra previamente preparada, adicionada do caldo UVM e cominuída, foi incubada em estufa a $30^{\circ} \mathrm{C}$ por 24 horas, para posteriormente ser transferido $0,1 \mathrm{~mL}$ da cultura para tubos contendo $10 \mathrm{~mL}$ de caldo Fraser (Acumedia ${ }^{\circledR} 7502 \mathrm{~A}$ ) adicionado de $0,1 \mathrm{~mL}$ do suplemento SR156 (Oxoid ${ }^{\circledR}$ X4196B) e incubado a $30^{\circ} \mathrm{C}$ por 48 horas. Após período de incubação foi verificada a ocorrência do escurecimento do meio, sendo que nos casos positivos os tubos inoculados seguiram para o plaqueamento diferencial.

O inóculo de $10 \mathrm{~mL}$ proveniente de cada tubo de caldo Fraser positivo foi estriado em placas contendo 3 diferentes meios, o ágar Triptose (Himedia ${ }^{\circledR}$ M177) suplementado com ácido nalidíxico (ATN), o ágar Oxford (Himedia ${ }^{\circledR}$ M1145) adicionado do suplemento SR140E (Oxoid ${ }^{\circledR}$ X3813B) e o ágar Mc Bride Listeria (MMA) (Bacto ${ }^{\circledR}$ 0922176) suplementado com cicloheximida seguindo-se de incubação a $30^{\circ} \mathrm{C}$ por 48 horas. A confirmação bioquímica foi realizada por meio da verificação da produção de catalase, observação das características morfotintoriais, verificação do crescimento típico em meio semissólido, verificação da incapacidade de redução de nitrato e verificação da positividade nas reaçóes de vermelho de metila e Voges Proskauer (VM-VP), conforme preconizado em legislação (BrasiL, 2003).

\section{Diferenciação entre espécies}

As culturas que tinham confirmado as características do gênero Listeria foram submetidas a testes para identificação das espécies por meio das seguintes provas bioquímicas: produção de alfa-hemólise, CAMP teste e fermentação dos carboidratos manitol, ramnose e xilose (BrasiL, 2003).

\section{Teste de resistência aos antimicrobianos}

Após identificação, as culturas foram testadas quanto à sua resistência aos agentes antimicrobianos, conforme descrito por BAuer et al. (1966), com utilizaçâo de discos comerciais (Polisensidisc ${ }^{\circledR} 4 \times 6$ DME) impregnados com os compostos clindamicina $(2 \mu \mathrm{g})$, eritromicina $(15 \mu \mathrm{g})$, oxacilina $(1 \mu \mathrm{g})$, penicilina $\mathrm{G}(10 \mu \mathrm{g})$, teicoplamina $(30 \mu \mathrm{g})$, vancomicina $(30 \mu \mathrm{g})$, aztreonam $(30 \mu \mathrm{g})$, cefoxitina $(30 \mu \mathrm{g})$, ceftriaxona $(30 \mu \mathrm{g})$, gentamicina $(10 \mu \mathrm{g})$, cloranfenicol $(30 \mu \mathrm{g})$ e tetraciclina $(30 \mu \mathrm{g})$. A leitura dos resultados foi realizada medindo o tamanho das zonas de inibição de crescimento bacteriano com um halômetro, sendo a estirpe bacteriana classificada como resistente, intermediária e sensível, de acordo com o diâmetro da zona padráo estabelecida na tabela fornecida pelo laboratório fabricante dos antimicrobianos.

\section{Avaliação estatística}

Os dados e resultados foram avaliados por meio do programa SPSS Statistics 17 (Windows \& Mac), utilizando o teste exato de Fisher para avaliação das análises de proporção de amostras contaminadas, nos grupos bar e restaurante. Para a comparação da eficiência dos meios utilizados na determinação da positividade para Listeria spp. utilizou-se o teste de McNemar. Em todas as análises foi adotado um nível de significância de 5\%.

\section{RESULTADOS}

De acordo com os resultados das análises, 20 e 35\% das amostras obtidas, respectivamente, em restaurantes e bares, estavam contaminadas com Listeria spp. Não houve diferença estatística significativa $(\mathrm{p}=1,000)$ quanto à proporção de amostras contaminadas entre bares e restaurantes.

Com relaçáo à incidência de espécies de Listeria, foram isoladas 22 estirpes, sendo: $L$. welshimeri isolada com maior frequência, representada por $81,82 \%$ (18/22 estirpes), seguida por $L$. grayi, com $13,66 \%$ (3/22 estirpes) e L. monocytogenes com $4,55 \%$ (1/22). Não foram encontradas as espécies $L$. ivanovii, L. innoccua e $L$. seeligeri.

É necessário ressaltar que das 22 estirpes identificadas, 19 foram isoladas por plaqueamento em meio seletivo Oxford, representando $86,4 \%$, sendo esse o meio mais eficiente para o isolamento de Listeria spp. em carpaccio de carne, neste estudo. O ágar MMA apresentou uma frequência de isolamento reduzida, apenas 3 estirpes, correspondendo a 13,6\%. O ágar ATN, apesar de ser o meio recomendado pelo método oficial para realização da análise de L. monocytogenes em produtos cárneos (BrasiL, 2003), não se mostrou eficiente neste trabalho. Estatisticamente, houve diferença significativa entre os isolamentos realizados com o ágar Oxford e o ágar MMA $(\mathrm{p}=0,039)$, sendo o ágar Oxford considerado o mais eficiente.

As estirpes isoladas e identificadas foram submetidas ao teste de sensibilidade aos agentes antimicrobianos, cujos resultados constam na Tabela 1 .

As estirpes de Listeria spp. foram resistentes, com variaçóes de percentuais, a todos os agentes antimicrobianos testados, exceto à tetraciclina, sendo que na presença desse composto os isolados apresentaram sensibilidade em graus variados. 
Tabela 1. Comportamento das espécies de Listeria isoladas de carpaccio, frente aos agentes antimicrobianos.

\begin{tabular}{lccc} 
Antimicrobiano & \multicolumn{3}{c}{ Comportamento } \\
\cline { 2 - 4 } & $\begin{array}{c}\text { Resistente } \\
\mathbf{n}(\%)\end{array}$ & $\begin{array}{c}\text { Intermediário } \\
\mathbf{n}(\%)\end{array}$ & $\begin{array}{c}\text { Sensível } \\
\mathbf{n}(\%)\end{array}$ \\
Clindamicina & $5(22,7)$ & $10(45,5)$ & $7(31,8)$ \\
\hline Eritromicina & $4(18,2)$ & $2(9,1)$ & $16(72,7)$ \\
\hline Oxaciclina & $4(18,2)$ & $1(4,5)$ & $17(77,3)$ \\
\hline Penicilina G & $4(18,2)$ & - & $18(81,8)$ \\
\hline Teicopamina & $2(9,1)$ & - & $20(90,9)$ \\
\hline Vancomicina & $2(9,1)$ & - & $20(90,9)$ \\
\hline Aztreonam & $14(63,6)$ & $3(13,6)$ & $5(22,7)$ \\
\hline Cefoxitina & $2(9,1)$ & $1(4,5)$ & $19(86,4)$ \\
\hline Gentamicina & $1(4,5)$ & - & $21(95,5)$ \\
\hline Tetraciclina & - & $1(4,5)$ & $21(95,5)$ \\
\hline Cloranfenicol & $3(13,6)$ & - & $19(86,4)$ \\
\hline Ceftriaxona & $12(54,5)$ & $2(9,1)$ & $8(36,4)$ \\
\hline
\end{tabular}

Nota-se que a maior resistência ocorreu frente aos antimicrobianos aztreonam e ceftriaxona, e que $68,75 \%$ das estirpes apresentaram comportamento multirresistente, ou seja, apresentaram resistência a dois ou mais agentes antimicrobianos.

\section{DISCUSSÃO}

Tendo em vista que, no Brasil, não há padrão estabelecido em legislação para Listeria spp. em produtos de origem animal, a simples presença do micro-organismo no alimento pode ser considerada de alto risco aos consumidores. Corroborando os resultados encontrados, muitos autores comprovam a presença frequente de Listeria spp. em produtos de origem animal, como Soriano et al. (2001), que avaliaram alimentos crus e prontos para o consumo provenientes de restaurantes e verificaram a presença de Listeria spp. em 30\% das amostras. MANTILla et al. (2007), analisando amostras de carne bovina moída resfriada, obtiveram uma frequência de $50 \%$ das amostras contaminadas com Listeria spp. De forma semelhante, KovaCEvic et al. (2012) encontraram $20 \%$ das amostras de alimentos prontos para consumo contaminados com esse micro-organismo.

Em plantas de processamento de carne bovina, a contaminação por Listeria spp. e a presença de L. monocytogenes em equipamentos e/ou utensílios também podem representar alto risco pela possibilidade de incorporação do patógeno ao produto final. Tal fato pode servir como subsídio para órgãos oficiais de saúde na adoção de medidas necessárias para eliminação ou redução de riscos associados a esse patógeno, além de conscientização do pessoal envolvido no processamento da carne, incentivando as boas práticas na manipulação (BARros et al., 2004).
Assim como verificado no presente estudo, KovaCEvic et al. (2012) também comprovaram que a L. welshimeri foi a espécie isolada com maior frequência, com $50 \%$ do total de listerias. Em contra partida, Soriano et al. (2001) encontraram apenas $1,9 \%$ de L. welshimeri, tendo como a espécie mais frequente a L. grayi, com 13,6\% em alimentos crus e prontos para o consumo. A baixa ocorrência de L. monocytogenes também foi reportada no trabalho de Yücel et al. (2005), que relataram uma frequência reduzida dessa espécie em carnes bovinas, moídas e inteiras, e carne de frango, sendo que somente $6,16 \%$ das amostras estavam contaminadas. Samadpour et al. (2006) e Mantilla et al. (2007) também observaram uma quantidade pequena de carnes moídas contaminadas com L. monocytogenes, 3,5 e 6,7\% respectivamente. Apesar das baixas ocorrências, verifica-se que esses alimentos ainda representam risco para saúde dos consumidores.

Com relação aos ágares de isolamento para Listeria spp., Mantilla et al. (2008b) compararam três meios de plaqueamento: o ágar lithium chloride phenylethanol moxalactam (LPM), o ágar MMA e o ágar Oxford. E, de acordo com os resultados apresentados, o ágar Oxford, assim como neste trabalho, foi caracterizado como mais eficiente para o isolamento de L. innocua e L. monocytogenes, sendo que no ágar LPM náo ocorreu o isolamento de nenhuma colônia de L. innocua e no ágar MMA nenhuma de L. monocytogenes.

Considerando o perfil de resistência antimicrobiana, YüCEL et al. (2005) também isolaram espécies de Listeria, oriundas de carne bovina e produtos cárneos, evidenciando a multirresistência a mais de um agente antimicrobiano, principalmente frente à ampicilina, cefalotina e ácido nalidíxico. Mantilla et al. (2008a) estudaram a resistência de Listeria spp. isoladas de carne moída e verificaram que todas as estirpes de L. monocytogenes apresentaram resistência aos antimicrobianos clindamicina, oxaciclina, gentamicina, sulfazotrim, cefoxitina e ampicilina. Também foram encontradas estirpes dessa mesma espécie resistentes a outros antimicrobianos indicados no tratamento da listeriose humana como, por exemplo, a tetraciclina e a eritromicina. Dos isolados testados, $100 \%$ foram resistentes a dois ou mais antimicrobianos. Ruiz-Bolivar et al. (2011), analisando alimentos provenientes de diferentes cidades da Colômbia, verificaram alta resistência das estirpes de Listeria frente à clindamicina, rifampicina, ciprofloxacino e a antimicrobianos de primeira escolha contra listeriose.

A existência de estirpes de Listeria spp. resistentes aos antimicrobianos utilizados rotineiramente no tratamento da listeriose humana representa um sério problema para a saúde coletiva, principalmente para os indivíduos que fazem parte do grupo de risco da listeriose, que incluem os idosos, crianças, mulheres grávidas e imunodeprimidos (Mantilla et al., 2008a). 


\section{CONCLUSÕES}

Os resultados aqui apresentados contribuem como dados sobre a exposição e a incidência de Listeria spp. em carpaccios de carne bovina comercializados em bares e restaurantes. Tendo em vista as avaliaçóes de riscos recentes de L. monocytogenes em alimentos, pode-se inferir que há um risco considerável para os consumidores desse produto em adquirir a listeriose. $\mathrm{O}$ consumo de carpaccios, que náo são produtos submetidos a tratamento térmico, pode representar um risco particular se náo forem manipulados corretamente e armazenados adequadamente sobre refrigeraçáo.

A espécie isolada com maior frequência foi L. welshimeri, seguida da L. grayi e L. monocytogenes, sendo o ágar Oxford o meio de plaqueamento mais eficiente para isolamento de Listeria spp. Pelo exposto, sugere-se a inclusão do ágar Oxford como meio indicado para o isolamento de Listeria spp. de produtos cárneos, como o carpaccio.
A confirmação de estirpes resistentes aos principais agentes antimicrobianos utilizados no tratamento de listeriose e a alta taxa de multirresistência constituem um grave problema de saúde coletiva, especialmente para indivíduos que fazem parte do grupo de risco. A possibilidade do aparecimento de bactérias com potencial patogênico, selecionadas quanto ao caráter de resistência aos antimicrobianos, reforça a importância das pesquisas envolvendo micro-organismos emergentes associados a perfis de resistência.

\section{AGRADECIMENTOS}

À Coordenação de Aperfeiçoamento de Pessoal de Nível Superior (CAPES), pelo apoio financeiro.

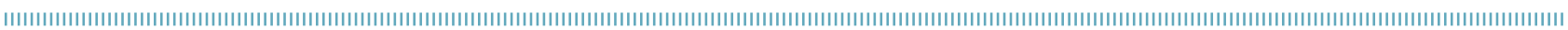
REFERÊNCIAS

BARROS, M.A.F.; BELOTI, V.; HAGA, M.M.; CAVALETTI, L.; D’OVÍDIO, L.; MONTEIRO, F.A.; NERO, L.A. Listeria spp. ocorrência em equipamentos e ambientes de processamento de carne bovina. Semina: Ciências Agrárias, v.25, n.4, p.341-348, 2004.

BAUER, A.W.; KIRBY, W.M.; SHERRIS, J.C.; TURCK, M. Antibiotic susceptibility testing by a standardized single disk method. American Journal of Clinical Pathology, v.45, n.4, p.493496, 1966.

BRASIL. Ministério da Agricultura, Pecuária e Abastecimento. Instrução Normativa n 62, de 26 de agosto de 2003. Oficializa os métodos analíticos oficiais para análises microbiológicas para controle de produtos de origem animal e água. Diário Oficial da União. Brasília, 18 de setembro de 2003.

DI GIACOMO, R.F.; KOEPSELL, T.D. Sampling for detection of infection or disease in populations. Journal of the American Veterinary Medical Association, v.189, n. 1, p.22-23, 1986.

FRANCO, B.D.G.M.; LANDGRAF, M. Microbiologia dos alimentos. São Paulo: Editora Atheneu, 2007. 182p.

HOLT, J.P.; KRIEG, N.R.; SNEATH, P.H.A.; STALEY, J.T.; WILLIAMS, S,T. Regular, nonsporing Gram positive rods. In:__. Bergey's manual of determinative bacteriology. 9th. ed. Baltimore: Williams \& Wilkins, 1994. 787p. Group 19, p.566-567.

INGHAM, S.C.; BEUGE, D.R.; DROPP, B.K.; LOSINSKI, J.A. Survival of Listeria monocytogenes during storage of readyto-eat meat products processed by drying, fermentation, and/or smoking. Journal of Food Protection, v.67, n.12, p.2698-2702, 2004.
KOVACEVIC, J.; MESAK, L.R.; ALLEN, K.J. Occurrence and characterization of Listeria spp. in ready-to-eat retail foods from Vancouver, British Columbia. Food Microbiology, v.30, n.2, p.372-378, 2012.

LUCQUIN, I.; ZAGOREC, M.; CHAMPOMIER-VERGĖS, M.; CHAILLOU, S. Fingerprint of lactic acid bacteria population in beef carpaccio is influenced by storage process and seasonal changes. Food Microbiology, v.29, n.2, p.187-196, 2012.

MANTILLA, S.P.S; FRANCO, R.M; OLIVEIRA, L.A.T; SANTOS, E.B.; GOUVÊA, R. Ocorrência de Listeria spp. em amostras de carne bovina moída comercializadas no município de Niterói, RJ, Brasil. Ciência e Agrotecnologia, v.31, n.4, p.1225-1230, 2007.

MANTILLA, S.P.S; FRANCO, R.M; OLIVEIRA, L.A.T; SANTOS, E.B.; GOUVÊA, R. Resistência antimicrobiana de bactérias do gênero Listeria spp. isoladas de carne moída bovina. Brazilian Journal of Veterinary Research and Animal Science, v.45, n.2, p.1 16-121, 2008 a.

MANTILLA, S.P.S; FRANCO, R.M; OLIVEIRA, L.A.T; GOUVÊA, R.; SANTOS, E.B.S. Comparação entre a eficiência de três meios de plaqueamento no isolamento de Listeria spp., a partir de carne moída. Higiene Alimentar, v.22, n. 166/167, p.166-171, 2008b.

MARTIN, S.W.; MEEK, A.H.; WILLEBERG, P. Veterinary epidemiology: principles and methods. Anes: lowa State University Press, 1987. 343p.

MIDURA, T.F.; BRYANT, R.G. Sampling Plans, sample collection, shipment, and preparation for analysis. In: DOWNES, F.P; ITO, K. Compendium of Methods for the Microbiological Examination of Foods. 4th.ed. Washington: American Public Health Association (APHA), 2001. Chap. 2, p.13-23. 
ORDÓÑEZ, J.A. Tecnologia de alimentos volume II: alimentos de origem animal. Trad. Fátima Murad. Porto Alegre: Artmed, 2005. 279p.

RUIZ-BOLIVAR, Z.; NEUQUE-RICO, M.C.; POUTOU-PIÑALES, R.A.; CARRASCAL-CAMACHO, A.K.; MATTAR, S. Antimicrobial susceptibility of Listeria monocytogenes food isolates from different cities in Colombia. Foodborne Pathogens and Disease, v.8, n.8, p.913-919, 2011.

SAMADPOUR, M.; BARBOUR, M.W.; NGUYEN, T.; CAO, T.M.; BUCK, F.; DEPAVIA, G.A.; MAZENGIA, E.; YANG, P.; ALFI, D.; LOPES, M.; STOPFORTH, J.D. Incidence of enterohemorrhagic Escherichia coli, Escherichia coli 0157, Salmonella and Listeria monocytogenes in retail fresh ground beef, sprouts, and mushrooms. Journal of Food Protection, v.69, n.2, p.441443, 2006.

SILVA, N.; JUNQUEIRA, V.C.A.; SILVEIRA, N.F.A.; TANIWAKI, M.H.; SANTOS, R.F.S.; GOMES, R.A.R. Manual de métodos de análises microbiológica de alimentos e água. 4a.ed. São Paulo: Livraria Varela, 2010.632p.

SORIANO, J.M.; RICO, H.; MOLTO, J.C.; MAÑES, J. Listeria species in raw and ready-to-eat foods from restaurants. Journal of Food Protection, v.64, n.4, p.551-553, 2001.

YÜCEL, N.; ÇITAK, S.; ÖNDER, M. Prevalence and antibiotic resistance of Listeria species in meat products in Ankara, Turkey. Food Microbiology, v.22, n.2-3, p.241-245, 2005. 